\title{
Influence of macroporosity on NIH/3T3 adhesion, proliferation, and osteogenic differentiation of MC3T3-E1 over bio-functionalized highly porous titanium implant material
}

\author{
A. C. Alves $\mathbb{D}^{1},{ }^{1}$ R. Thibeaux, ${ }^{2}$ F. Toptan, ${ }^{1,3,4}$ A. M. P. Pinto, ${ }^{1,3}$ P. Ponthiaux, ${ }^{5}$ B. David ${ }^{2}$ \\ ${ }^{1}$ CMEMS-UMinho - Center of MicroElectroMechanical Systems - Universidade do Minho, Campus de Azuém, Guimarães, Portugal \\ ${ }^{2}$ MSSMat, Laboratoire de Mécanique des Sols, Structures et Matériaux, UMR CNRS 8579, CentraleSupélec, Université Paris \\ Saclay, Châtenay-Malabry, France \\ ${ }^{3}$ DEM - Departament of Mechanical Engineering - Universidade do Minho, Campus de Azurém, Guimarães, Portugal \\ ${ }^{4} \mathrm{IBTN} / \mathrm{Br}$ - Brazilian Branch of the Institute of Biomaterials, Tribocorrosion and Nanomedicine, UNESP, Campus de Bauru, \\ Bauru, SP, Brazil \\ ${ }^{5}$ LGPM, Laboratoire de Génie des Procédés et Matériaux, CentraleSupélec, Université Paris Saclay, Châtenay-Malabry, France
}

Received 26 October 2017; revised 5 February 2018; accepted 12 February 2018

Published online 8 March 2018 in Wiley Online Library (wileyonlinelibrary.com). DOI: 10.1002/jbm.b.34096

\begin{abstract}
Highly porous Ti implant materials are being used in order to overcome the stress shielding effect on orthopedic implants. However, the lack of bioactivity on Ti surfaces is still a major concern regarding the osseointegration process. It is known that the rapid recruitment of osteoblasts in bone defects is an essential prerequisite for efficient bone repair. Conventionally, osteoblast recruitment to bone defects and subsequent bone repair has been achieved using growth factors. Thus, in this study highly porous Ti samples were processed by powder metallurgy using space holder technique followed by the bio-functionalization through microarc oxidation using a Caand P-rich electrolyte. The biological response in terms of early
\end{abstract}

cell response, namely, adhesion, spreading, viability, and proliferation of the novel biofunctionalized highly porous Ti was carried out with $\mathrm{NIH} / 3 \mathrm{~T} 3$ fibroblasts and MC3T3-E1 preosteoblasts in terms of viability, adhesion, proliferation, and alkaline phosphatase activity. Results showed that bio-functionalization did not affect the cell viability. However, bio-functionalized highly porous $\mathrm{Ti}(22 \%$ porosity) enhanced the cell proliferation and activity. (C) 2018 Wiley Periodicals, Inc. J Biomed Mater Res Part B: Appl Biomater 107B: 73-85, 2019.

Key Words: bio-functionalization, microarc oxidation, porous Ti, osseointegration

How to cite this article: Alves AC, Thibeaux R, Toptan F, Pinto AMP, Ponthiaux P, David B. 2019. Influence of macroporosity on NIH/3T3 adhesion, proliferation, and osteogenic differentiation of MC3T3-E1 over bio-functionalized highly porous titanium implant material. J Biomed Mater Res Part B 2019:107B:73-85.

\section{INTRODUCTION}

Titanium is a widely used material in biomedical implants due to the combination of the required properties, as excellent corrosion resistance, adequate biocompatibility, and mechanical properties. $^{1,2}$ However, the differences between the Young's modulus of the Ti implants and the bone (110 and 10-30 GPa, respectively) leads to stress shielding effect on the supporting bone. ${ }^{1,3-7}$ The use of highly porous structures with tailored porosity are becoming popular for implant materials particularly due to their adjustable Young's modulus to be similar to the bone, and at the same time, improved implant fixation. ${ }^{8,9}$

In order to increase the osseointegration through improving the bone/implant interface by accelerating bone healing, and improving bone anchorage to implant, two types of strategies are reported in the literature. First strategy is the physical modification of the material/bone interface by tailoring the surface topography with roughness, and/or porosity $^{10-12}$ aiming to increase bone cell migration, proliferation, and finally osseointegration. ${ }^{13-15}$ Second strategy is the chemical modification of the implant material surface to improve its bioactivity, thus to stimulate bone regeneration and increase the biochemical interlocking. ${ }^{16-20}$ At the cellular scale, this is reflected by the following steps: cells recruitment, proliferation on and within the surface, and finally, differentiation in bone tissue.

Within the first strategy, Park et al. ${ }^{21}$ reported an enhanced initial cell attachment and spreading on microrough surfaces, being in agreement with other studies reporting better adhesion and spreading of oestoblastic cells on grit-blasted or

Correspondence to: A. C. Alves; e-mail: alexandra@dem.uminho.pt

Contract grant sponsor: FCT; contract grant number: UID/EEA/04436/2013

Contract grant sponsor: FEDER (COMPETE 2020 - Programa Operacional Competitividade e Internacionalização [POCI]); contract grant number: POCl-01-0145-FEDER-006941

Contract grant sponsor: Programa de Acções Universitárias Integradas Luso-Francesas; contract grant number: PAUILF TC-12_14 
grit-blasted/etched microrough surfaces compared with relatively smooth machined surfaces.

Porosity is known as an important surface parameter regarding osseointegration of orthopedic implants. Osseointegration on porous $\mathrm{Ti}$ takes place by the bone growth into the pores, allowing a good biological fixation. ${ }^{22,23}$ Moreover, structures with high porosity present greater surface contact at implant-bone interface giving more space for bone ingrowth and mechanical interlocking. ${ }^{24,25}$ During the integration of the prostheses to the bone, porosity can allow the bone cells to penetrate into the implant and thus ensuring, in theory, a better long-term stability of the prosthesis (decreasing the micromovements), as well as can facilitate vascularization of the tissues. Therefore, the size and structure of the pores must be considered for an optimal biological response of the implant. However, there is no consensus on the ideal pore diameter or morphology. ${ }^{14}$ Besides, Kuboki et al. $^{26}$ showed that interconnected pores allow tissue and bone ingrowth leading to anchor the prosthesis to the surrounding bone preventing and helping to hold the dynamic strength of the implant. Karageorgiou et al. ${ }^{13}$ suggested gradients in pore size for the formation of multiple tissues and tissue interfaces. Several studies ${ }^{13,14,27,28}$ have shown that the minimum pore size for significant bone growth should be between 75 and $100 \mu \mathrm{m}$, but the optimal range was observed between 100 and $135 \mu \mathrm{m}$. However, in order to promote bone formation and vascularization, pores larger than $300 \mu \mathrm{m}$ are needed.

Although $\mathrm{Ti}$ is the most biocompatible metallic material, its lack of bioactivity cannot induce bone regeneration or directly bond with bone in the early stage after implantation. ${ }^{16}$ In order to overcome these issues, several surface modifications are being used. ${ }^{29-31}$ (the second strategy). Among these techniques, microarc oxidation (MAO) allows to create thick, adherent, porous titanium oxide films with the incorporation of bio-active elements, as well as allows to tailor crystallinity and morphological characteristics in a way to improve the biological properties of $\mathrm{Ti}^{30,31}$

For instance, Gorgin Karaji et al. ${ }^{32}$ studied the effect of bio-functionalization of the additively manufactured Ti6Al4V scaffolds by plasma electrolytic oxidation (PEO) to their mechanical properties and reported that the treatment time can significantly affect the mechanical properties such as Young's modulus, yield stress, and plateau stress. Moreover, it has been reported that different surface treatment processes can affect the mechanical properties of porous titanium material. ${ }^{32-35}$

Several studies ${ }^{6,36-42}$ had shown that MAO treatment on Ti surfaces enhanced its biological response. Alves et al. ${ }^{38}$ performed PEO on commercial pure Ti and studied the biological properties of Ca-and P-enriched layers assessed for osteoblastic cell viability/proliferation ability. The authors concluded that cell viability/proliferation was improved on PEO treated samples. Some of the present authors have also reported recently ${ }^{43}$ that bio-functionalization of highly porous Ti by MAO improved the tribocorrosion behavior owing both to improved corrosion behavior through the oxide layers formed on the inner and outer pore surfaces, and improved wear resistance through the increased hardness of the anodic layers. However, surface functionalization parameters should be carefully selected in order to attain the desired properties.

On the other hand, Ribeiro et al. ${ }^{39}$ showed that MAO treated Ti surfaces with Ca- and P-rich layers shown to be the main factor leading to a faster osteoblast adhesion and spreading. As well, Teker et al. ${ }^{44}$ performed MAO on Ti (grade 4) using a $\mathrm{Ca}$ and $\mathrm{P}$ containing electrolyte and reported that Ca- and P-rich layers accelerated biomimetic precipitation of apatite in simulated body fluid and exhibited better antibacterial efficiency. Moreover, hydroxyapatite (HAP) crystals can be precipitate on the anodic Ca- and P-rich surfaces by a hydrothermal treatment after MAO. It is been reported that osteoconductivity of Ca- and P-rich anodic oxide films is induced by the presence of HAP crystals. ${ }^{45-49}$

According to Carré and Lacarrière, ${ }^{50}$ cell adhesion process consists of four steps: protein adsorption; cell-substrate contact; cell-substrate attachment; and cell-cell interaction. These steps are influenced by several factors, such as roughness, porosity, wettability, surface energy, topography, polarity, charge, chemical composition, among others. Biological response depends also on surface characteristics and/or surface treatments applied on the material. Moreover, the biological response to a new material is primarily evaluated in vitro, through the analysis of cell adhesion, proliferation, and viability. The knowledge of these cell-biomaterial interactions may suggest modifications in the structure or composition of biomaterial that can improve this interaction. ${ }^{51}$ In order to understand the biological response of a new material, firstly it is important to study its cytotoxicity, followed by the interactions that occur between cells and material surface.

Although some studies are available in the literature on the biological response of MAO-modified dense Ti surfaces, and highly porous $\mathrm{Ti}$ structures, separately, the combined influence of the three-dimensional (3D) macroporous architecture and bio-functionalization on the biological response is yet to be understood. Thus, the aim of this work was to investigate the effect of macroporosity on the biological response of bio-functionalized highly porous Ti. Highly porous Ti samples were processed by powder metallurgy using the space holder technique followed by its biofunctionalization by $\mathrm{MAO}$, using an electrolyte rich in bioactive elements, namely $\mathrm{Ca}$ and $\mathrm{P}$. Early cell response in terms of adhesion, spreading, viability, and proliferation was assessed by fibroblast and osteoblast attachment, proliferation, morphology, and viability in order to validate the performance of bio-functionalized highly porous structures.

\section{MATERIALS AND METHODS \\ Materials and processing}

Ti foams having 30 and $50 \mathrm{vol} \%$ of nominal porosity were processed by powder metallurgy using space holder technique (hereafter will be given as Ti22 and Ti37, respectively, due to the real porosity values previously measured by image analysis ${ }^{52}$ ). Ti powders having average size of 25 $\mu \mathrm{m}$, urea particles under $500 \mu \mathrm{m}$, and PVA (0.4 vol \%) as binder were used to process highly porous samples. Dense 


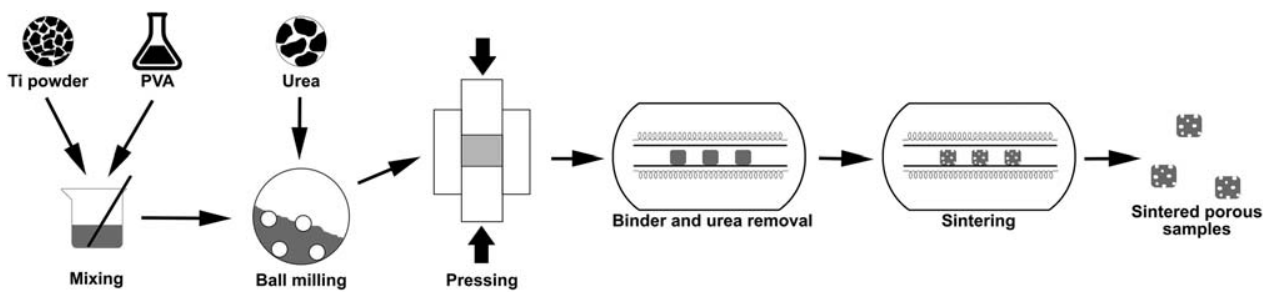

FIGURE 1. Schematic representation for powder metallurgy with space holder technique.

Ti samples were also produced under identical conditions but without the addition of urea, to be used as a control group.

A ball mill rotating with alumina balls at $130 \mathrm{rpm}$ during $4 \mathrm{~h}$ was used to mix Ti, urea and PVA. Powders blends were uniaxially pressed in zinc stearate lubricated nitrided stainless steel die under $350 \mathrm{MPa}$ for $2 \mathrm{~min}$. Binder and space holder removal was performed under Ar atmosphere at $450^{\circ} \mathrm{C}$ during $3 \mathrm{~h}$. After, the samples were heated up to $1100^{\circ} \mathrm{C}$ with $5^{\circ} \mathrm{C} / \mathrm{min}$ heating rate and sintered during $3 \mathrm{~h}$ in horizontal tubular furnace under high vacuum $\left(<10^{-5}\right.$ mbar) (Figure 1). The samples presented a cylindrical geometry with $12 \mathrm{~mm}$ of diameter and $3 \mathrm{~mm}$ of thickness.

\section{Bio-functionalization of porous Ti by MAO}

Prior to the MAO treatment the samples were etched with Kroll's reagent $\left(88 \% \mathrm{H}_{2} \mathrm{O}, 2 \% \mathrm{HF}\right.$, and $\left.10 \% \mathrm{HNO}_{3}\right)$ for $30 \mathrm{~s}$, and cleaned ultrasonically for $15 \mathrm{~min}$ in propanol followed by $10 \mathrm{~min}$ in distilled water, and then dried with warm air. The MAO treatment was performed in constant voltage mode. A direct current power supply (GPR-30H10D) was used and the treatment was carried out for $1 \mathrm{~min}$ at $300 \mathrm{~V}$ in an electrolyte containing a solution of $\beta$-glycerophosphate disodium salt pentahydrate ( $\beta$-GP, $0.02 M)$ and calcium acetate monohydrate $(0.35 M)$. Samples having a geometric exposed area of $3.39 \mathrm{~cm}^{2}$ were used as anode, positioned $8 \mathrm{~cm}$ away from a platinum plate with an exposed area of $12.57 \mathrm{~cm}^{2}$ that was used as the cathode. MAO treatments were done under agitation in a turbulent regime by using a magnetic stirrer rotating at $200 \mathrm{rpm}$. After MAO treatments, samples were ultrasonically cleaned in propanol for $10 \mathrm{~min}$ followed by distilled water during $5 \mathrm{~min}$, and then dried with warm air. All biofunctionalized samples are identified as "-AT."

\section{Biological tests}

First, in order to evaluate the most promising surfaces in terms of cell attachment, viability, and growth, murine fibroblasts NIH/ 3T3 (ATCC) were seeded on as-etched and bio-functionalized samples. Then, murine calvaria-derived MC3T3-E1 preosteoblastic (ATCC) were seeded just on bio-functionalized samples, which showed the best results in terms of adhesion, viability, and proliferation with fibroblast cells. Osteoblastic cells for long time of culture used for understanding and estimating the cell differentiation and later the bone formation.

Prior to cellular seeding, the samples were autoclaved (Advantage Lab AL02-01, $18 \mathrm{~min}, 105^{\circ} \mathrm{C}, 220 \mathrm{kPa}$ ) and kept in incubator at $37^{\circ} \mathrm{C}$ in a humidified atmosphere of $5 \% \mathrm{CO}_{2}$ 95\% air.
Cell lines and drug treatment. NIH/3T3 (ATCC) were routinely cultured in DMEM Glutamax (Gibco, Life Technologies) supplemented with 10\% fetal bovine serum (Pan-Biotech). The murine calvaria-derived MC3T3-E1 preosteoblastic cell line from ATCC were grown in $\alpha$-MEM medium containing 50 $\mu \mathrm{g} / \mathrm{mL}$ of ascorbic acid (Gibco, Life Technologies) and supplemented with $10 \%$ of fetal calf serum (Pan-Biotech). All cultures were maintained at $37^{\circ} \mathrm{C}$ in a humidified atmosphere of $5 \% \mathrm{CO}_{2}-95 \%$ air. Medium was changed every 3 days and cells were split at $70 \%$ confluence.

Cell proliferation and cellularization-NIH/3T3. As-etched and bio-functionalized samples were transferred into 12-wells culture plates where samples had $1.13 \mathrm{~cm}^{2}$ area exposed to cells. NIH/3T3 (ATCC) cells were seeded on the samples surfaces at 5000 cells $\mathrm{cm}^{-2}$ corresponding to total cell number of 5650 per sample. Cell proliferation, viability, and number of cells were evaluated after culturing for 24,48 , and $72 \mathrm{~h}$. NIH/ 3T3 fibroblasts viability and number of cells on samples were assayed with Live/Dead ${ }^{\circledR}$ Viability/Cytotoxicity Kit (ThermoFisher Scientific) according to the manufacturer's instruction. This kit is a two-color fluorescence assay that simultaneously determines dead and live cells. The results were observed by confocal laser scanning microscope (ZEISS Axioobserver LSM $700)$ by scanning all surface $\left(1.13 \mathrm{~cm}^{2}\right)$. The number of cells and the viability were determined by image analysis using ImageJ software (version 1.48). For each group of samples, the total number of cells was estimated through dividing the total area occupied by the cells to the average area of a cell on this material. The cell proliferation was observed using an inverted optical microscope (ZEISS Axiovert $40 \mathrm{CFL}$ ).

Differentiation cell culture conditions-MC3T3-E1. The same procedure described previously for NIH/3T3 was used to assess the viability of the experiments regarding the MC3T3-E1, but MC3T3-E1 were cultured for 30 days. MC3T3-E1 were amplified in $\alpha$-MEM media containing 50 $\mu \mathrm{g} / \mathrm{mL}$ of ascorbic acid for 9 days and then differentiation into osteoblastic-like cells was induced by adding $10 \mathrm{mM}$ of $\beta$-GP (Sigma-Aldrich), and $10^{-8} M$ of dexamethasone (SigmaAldrich). The culture medium was changed every 3 days.

Alkaline phosphatase activity assay-MC3T3-E1. Alkaline phosphatase activity (ALP) was measured as an early biomarker specific to osteoblast differentiation. ALP was determined using the colorimetric Alkaline Phosphatase Assay Kit (Abcam). The kit uses $p$-nitrophenyl phosphate (pNPP) as a phosphatase substrate which turns yellow (max $=405 \mathrm{~nm})$ when 

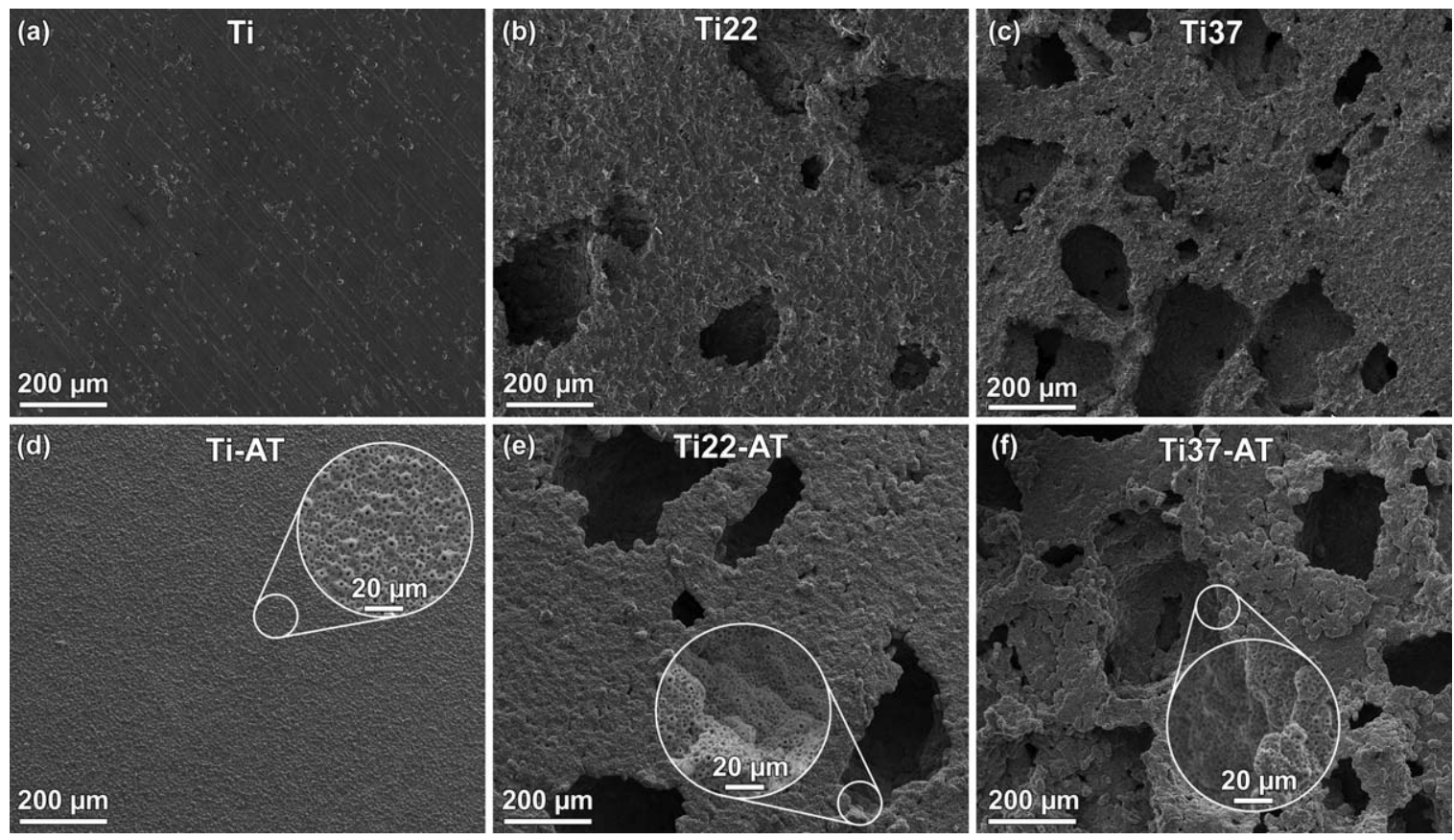

FIGURE 2. Representative SEM images of as-etched (a-c) and bio-functionalized surfaces (d-f).

dephosphorylated by ALP. The cell suspension $(80 \mu \mathrm{L})$ was added to $50 \mu \mathrm{L}$ of working reagent ( $5 \mathrm{mM}$ pNPP) and $10 \mu \mathrm{L}$ of enzyme. The samples were then incubated for $2 \mathrm{~h}$ at $37^{\circ} \mathrm{C}$. Afterward, the reaction was stopped and read with a microplate reader (Thermo Scientific, Multiskan GO) at $405 \mathrm{~nm}$.

The enzyme activity (expressed as units/g of total protein) was normalized by protein concentration detected by BCA protein assay kit (ThermoFisher Scientific).

Samples preparation for scanning electron microscopy. At different culture time points, the samples were fixed overnight (4\% PFA in PBS, Sigma-Aldrich), washed with PBS and stained during $2 \mathrm{~h}$ by $1 \%$ osmium tetroxide $\mathrm{CsO}_{4}$ in $\mathrm{PBS}$, Alpha Aesar). After that, samples were dehydrated at different concentrations of ethanol $(25,50,70,90,95$, and $100 \%$ ) and dried using hexamethyldisilazane (SigmaAldrich). For scanning electron microscopy (SEM) analysis, samples were coated with $\mathrm{Cr}$ at $1.2 \mathrm{kV}$.

Statistical analysis. The results were statistically analyzed through one-way analysis of variance followed by a post hoc testing (Tukey), using a significance level of $p<0.05$. All biological tests were repeated at least three times in order to ensure repeatability and the results are presented as average \pm standard deviation.

\section{Surface characterization}

Before and after biological studies, topography, microstructure, and chemical composition of the surfaces were observed by FEI Nova 200 field emission gun scanning electron microscope equipped with energy dispersive X-ray spectroscopy, and scanning electron microscope (JEOL JSM6010PLUS/LV), using secondary electron signals.

\section{RESULTS}

Physical properties: Microstructural characterization Representative SEM images of as-etched and bio-functionalized samples are shown in Figure 2. Some of the present authors had previously characterized highly porous $\mathrm{Ti}$ samples processed under identical conditions. ${ }^{52}$ In that work, it was reported that Ti22 and Ti37 samples presented most of the macropores ranging between 50 and $350 \mu \mathrm{m}$ in size. Closed macropores were found mostly in the case of Ti22 samples while a mixture of open (interconnected) and closed macropores was observed in Ti37 samples. The average macropore size was 230 and $200 \mu \mathrm{m}$ for Ti22 and Ti37 samples, respectively.

The grinded surfaces were homogenized by etching where the surface roughness $\left(S_{\mathrm{a}}\right)$ increased from 0.40 to $0.63 \mu \mathrm{m}^{43}$ after etching. However, as-etched Ti surfaces [Figure 2(a)] still presented grinding marks. After bio-functionalization, the surfaces exhibited the typical multiscale porous volcano-like structure and the grinding marks were not distinguishable. Furthermore, the surface roughness $\left(S_{\mathrm{a}}\right)$ increased to 1.27 $\mu \mathrm{m}^{43}$ after bio-functionalization. SEM observations also revealed that bio-functionalization was also successful on the porous samples surfaces since the pore surfaces were effectively covered by the anodic layers [Figure 2(e,f)].

The distribution of the interpore distance on the anodic layers is presented in Figure 3. Almost 50\% of the anodic pores presented interpore distance of 4-6 $\mu \mathrm{m}$ on Ti-AT and Ti22-AT samples, whereas Ti37-AT samples had around $50 \%$ of their anodic pores in the interpore distance range of 6-10 $\mu \mathrm{m}$.

\section{Chemical properties: Bio-functionalization of porous Ti by MAO}

The $\mathrm{Ca} / \mathrm{P}$ weight ratio of the anodic layers is presented in Table I. The results showed that bio-functionalization of 


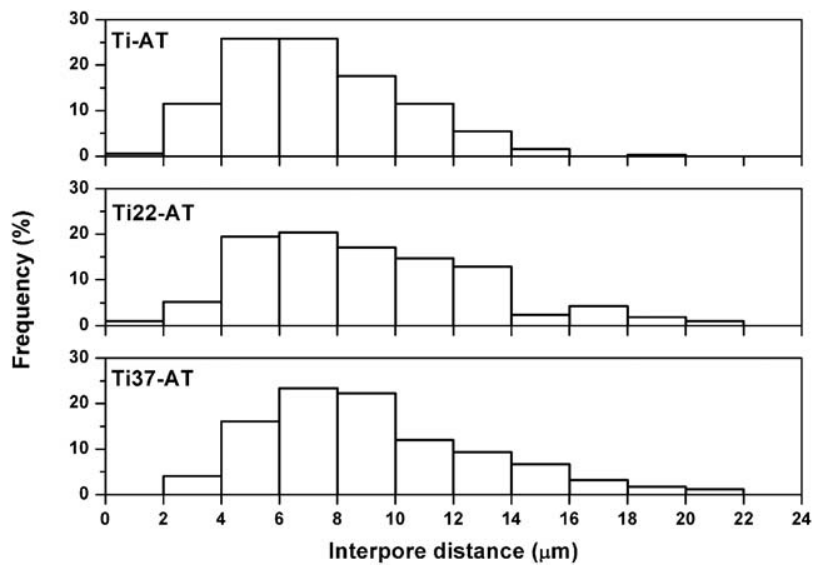

FIGURE 3. The distribution of the interpore distance on Ti-AT, Ti22AT, and Ti37-AT surfaces.

porous Ti was not influenced by the level of porosity since there were no significant differences on the $\mathrm{Ca} / \mathrm{P}$ ratio between the bio-functionalized porous $\mathrm{Ti}$ and dense Ti samples.

Microstructural and chemical analysis revealed that biofunctionalization of highly porous $\mathrm{Ti}$ was succeeded in terms of topography (increased surface roughness) and chemical composition by the incorporation of bioactive elements ( $\mathrm{Ca}$ and $\mathrm{P}$ ) into the anodic layers.

\section{Biological studies}

As-etched and bio-functionalized Ti: Quantification and observation of fibroblasts growth. Proliferation assay of fibroblasts cultured for the different culture time in the asetched and bio-functionalized samples is shown in Figure 4. As can be seen on the graph, the number of cells increased with the culture time in both groups. Although no statistically significant differences were observed on the number of cells among all groups, it can be observed that bio-functionalized surfaces showed a higher number of cells in all samples. In all cases, the viability of the fibroblasts was always higher than $96 \%$. This result is in a good agreement with the literature because it is well known that fibroblasts are highly substrate dependent connective tissue cells and early attachment on substrates is critical for their in vitro viability. The number of cells were more than double on all bio-functionalized surfaces when compared to the as-etched surfaces for the longest culture time. After $72 \mathrm{~h}$ of culture Ti-AT samples presented $5.8 \times$ $10^{6}$ cells while Ti had $1.8 \times 10^{6}$.

No significant difference was observed between Ti and Ti22 samples for all culture times. However, on bio-functionalized surfaces, Ti22-AT enhanced the cell proliferation presenting the higher number of cells during all culture time $\left(5.0 \times 10^{5}, 2.3 \times\right.$ $10^{6}$, and $7.3 \times 10^{6}$ cells, for 24,48 , and $72 \mathrm{~h}$ of culture time, respectively).

TABLE I. Ca/P Ratio Incorporated Into the Anodized Ti Layers

\begin{tabular}{lccc}
\hline & Ti-AT & Ti22-AT & Ti37-AT \\
\hline $\mathrm{Ca} / \mathrm{P}$ & $3.44 \pm 0.12$ & $3.41 \pm 0.13$ & $3.46 \pm 0.36$ \\
\hline
\end{tabular}

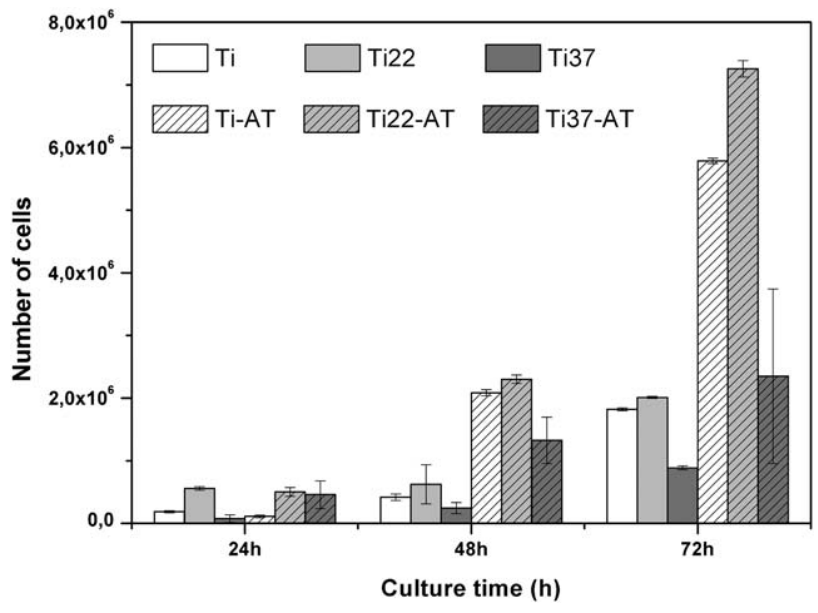

FIGURE 4. Proliferation assay of fibroblast cultured on different asetched and bio-functionalized (AT) Ti surfaces.

The surface homogeneity of the cell proliferation and morphology was assessed by fluorescence optical microscopy. Figure 5 presents microscopic fibroblasts proliferation observation for 4 and $72 \mathrm{~h}$ of culture for as-etched and biofunctionalized samples, respectively. It was observed in both cases that the area covered with cells increased with the culture time with exception of Ti37 samples. However, in the case of the bio-functionalized surfaces, a larger area was covered with cells. Ti22 and Ti37 as-etched and biofunctionalized samples also presented cells inside of the pores. At the first time-point $(4 \mathrm{~h})$, it was visible that fibroblasts adhesion was different on each surface. The area of surface covered by fibroblasts decreased from Ti to Ti22 and Ti37. Most of the macropores on Ti22 and Ti37 were filled by cells, mainly in the case of Ti37 as can be observed in Figure 5. Fibroblasts at $4 \mathrm{~h}$ of culture increased from TiAT to Ti22-AT, as can be seen on the green expression, representing the fibroblasts adhesion.

Regarding the homogeneity of the cells during proliferation with culture time, all surfaces presented a good cellularization, with exception of Ti37 and Ti37-AT. Comparing the as-etched and bio-functionalized surfaces, it was possible to observe that the bio-functionalization treatment enhanced the cell proliferation with more expression in the case of Ti22-AT samples.

Cell morphology is also shown in Figure 5, on the detailed images taken after $72 \mathrm{~h}$ of culture. It was possible to observe in all surfaces with the exception of Ti37 samples that most of the fibroblasts exhibited a spread and elongated morphology.

Effect of cell/biomaterial interface. Interface between cell and material surface was assessed by SEM micrographs showing the evolution of fibroblast morphology at 24 and $72 \mathrm{~h}$ of culture on as-etched and bio-functionalized surfaces (Figure 6). At $24 \mathrm{~h}$, cells were already adhered and spread on surfaces with some interconnecting structure among them. At $72 \mathrm{~h}$ of culture, the interconnecting structure among the cells was more visible together with cytoplasmic 


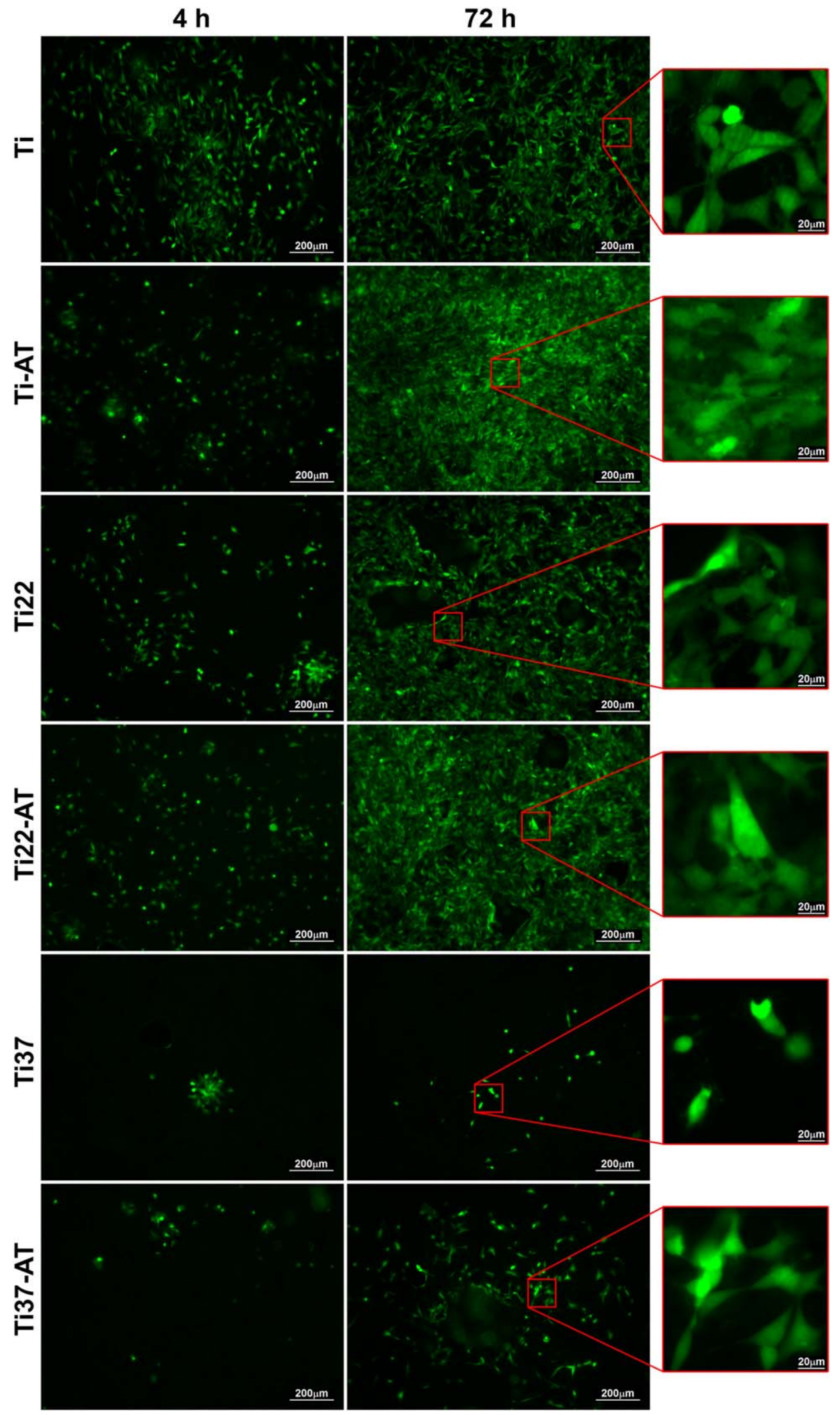

FIGURE 5. OM images of fibroblasts attached to the as-etched and bio-functionalized surfaces for 4 and $72 \mathrm{~h}$ of culture.

(cells) spreading, indicating a good adherence. In the case of as-etched and bio-functionalized Ti22 and T37 samples, after at $72 \mathrm{~h}$, cell ingrowth and interconnectivity by bridging macropores were visible. The cells attaching to highly porous surfaces elongated along the macropores and produced prominent filopodias. Moreover, the most outer 


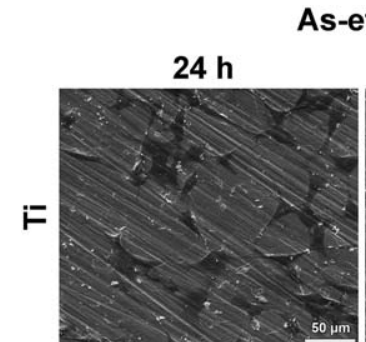

As-etched
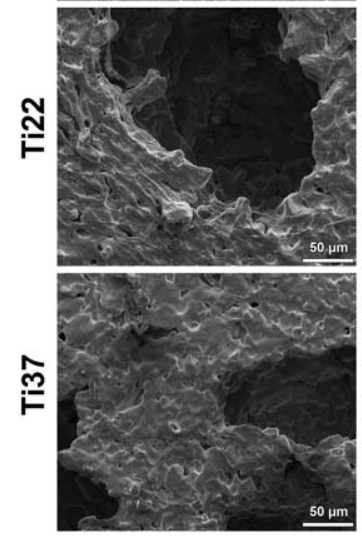
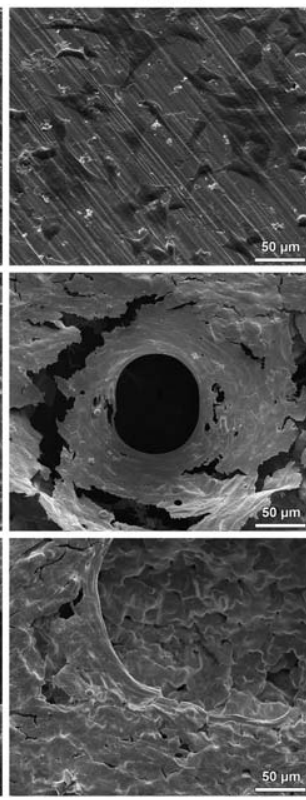

Bio-functionalized $24 \mathrm{~h}$
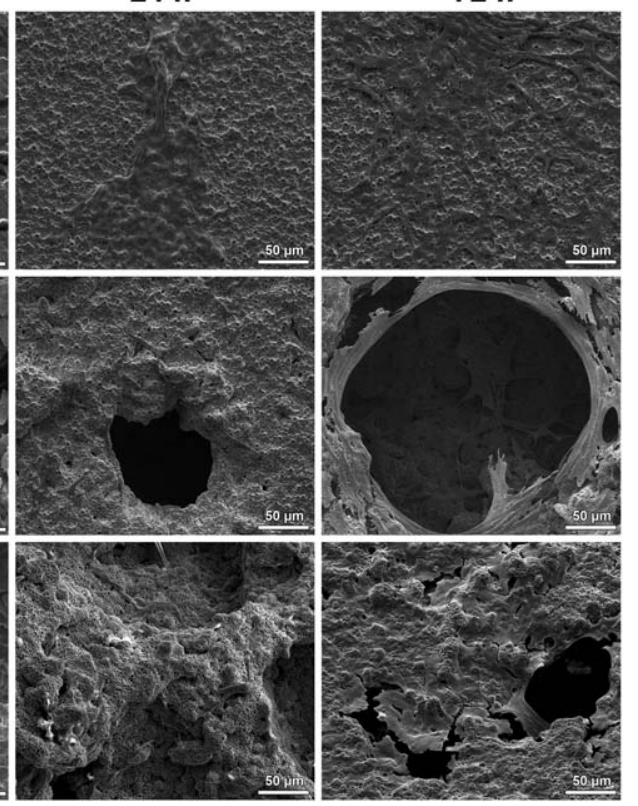

FIGURE 6. Representative SEM images of fibroblasts attached to as-etched and bio-functionalized surfaces for 24 and $72 \mathrm{~h}$ of culture.

and isolated macropores were filled up with cells. The attachment and migration of fibroblast cells even in large pore-size structures was observed, however for smaller macropores, there was an increased efficiency. In the case of as-etched Ti22 and Ti37 at $24 \mathrm{~h}$, filamentous network structure with cell-to-cell attachment was observed, and the cells spread along the grain boundaries. Additionally, after $72 \mathrm{~h}$ of culture, the fibroblast cells were spread on the surfaces and blocking the view of the grain boundaries which indicates an excellent growth of fibroblast cells on these structures. On the macropore scale, similar mechanisms of fibroblasts growth were observed on the bio-functionalized samples.

Contribution of MAO treatment to cell proliferation. In the case of bio-functionalized surface, confluent state was reached on Ti-AT and Ti22-AT samples (Figure 6). Besides, the fibroblasts appeared to be larger, more spread out and formed higher level of cell-cell contacts. As a result, it can be stated that fibroblast morphology and activity were enhanced on bio-functionalized surfaces.

Contribution of MAO treatment to cellularization. Detailed analysis of the surfaces after $72 \mathrm{~h}$ of fibroblast culture revealed an additional mechanism on the bio-functionalized surfaces. These surfaces presented cells with elongated extensions of cytoplasm (filopodia) by creating bridges between the tops of each volcano formed by MAO treatment (Figure 7). This cell morphology indicated a good cell-surface interaction not just due to the increased contact area, but also due to the modified chemical composition (rich in Ca and P) and crystalline structure (anatase and rutile). On this mechanism, cell-cell interactions were also observed to be favored due to cell morphology. When seeded, the average cell size is around $5 \mu \mathrm{m}$. As it is presented in Figure 3, some of the pores exhibited interpore distance shorter than the cell size that can allow cells to spread and create bridges between the pores.

Studies with fibroblasts revealed that both as-etched and bio-functionalized samples were biocompatible. Moreover, bio-functionalized $\mathrm{Ti}$ samples combined the most favorable conditions for cell growth.

Osteoblastic differentiation on bio-functionalized Ti. Cellularization. Figure 8 show the osteoblast cell colonization over all surface for Ti-AT, Ti22-AT, and Ti37-AT for 30 days of culture. A detailed cell-surface interaction can be seen on Figure 8(b, d, and f). It can be observed that osteoblast cells were well attached and spread onto the surfaces in all bio-functionalized samples. Detailed observation of the interaction of osteoblasts with the bio-functionalized

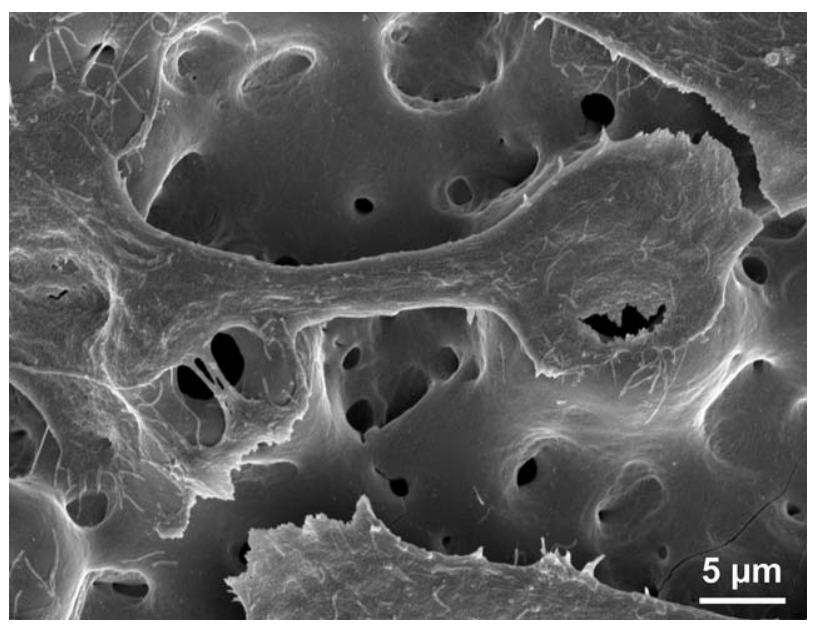

FIGURE 7. Representative higher magnification SEM image of fibroblasts attached to Ti-AT surfaces at $72 \mathrm{~h}$ of culture. 

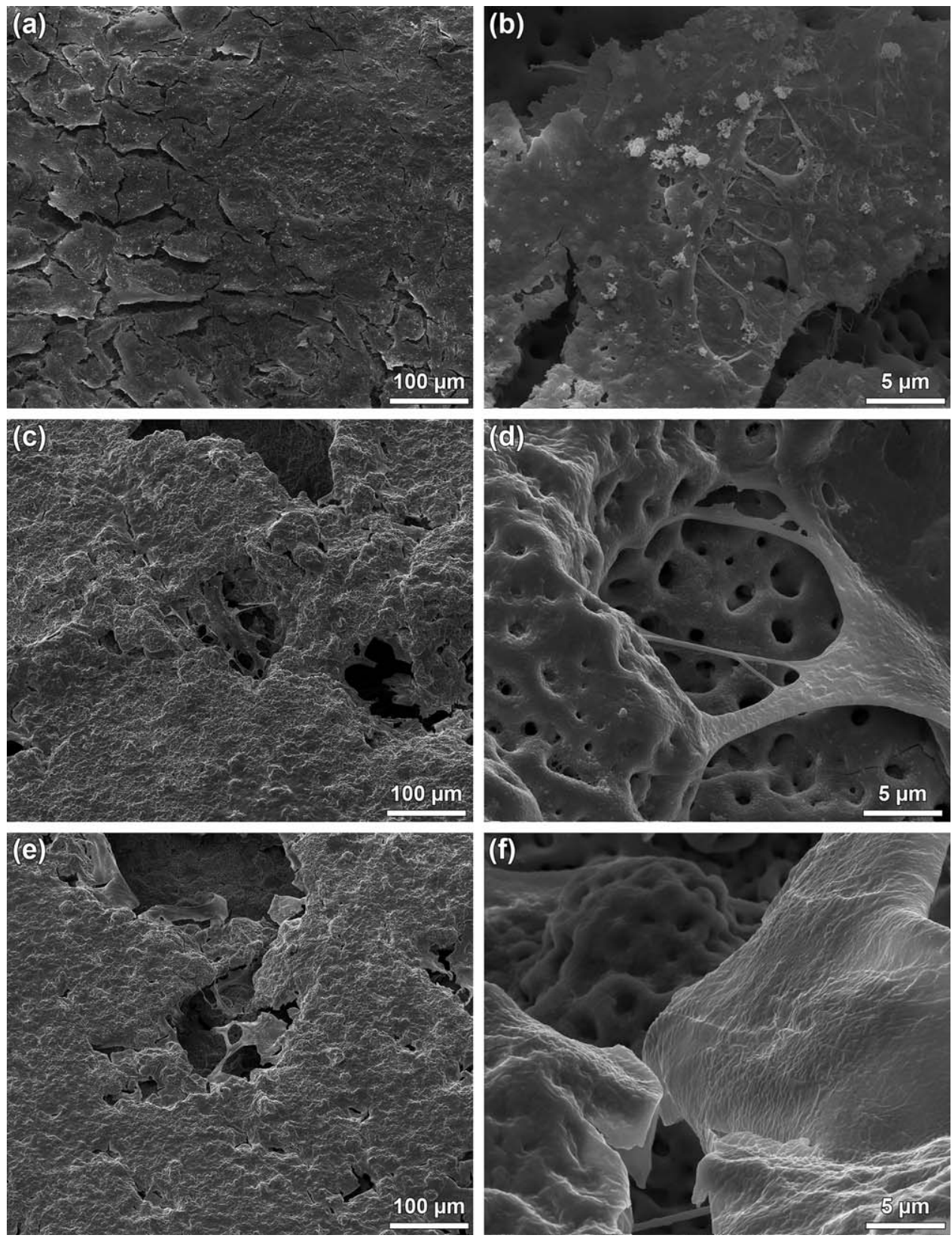

FIGURE 8. Representative lower and higher magnification SEM images of osteoblasts attached to Ti-AT (a,b), Ti22-AT (c,d), and Ti37-AT (e,f).

surfaces revealed that cells covered the anodic pores, hindering the visibility of the surface morphology. The cytoplasmatic extensions created bridges across the pores of anodic layers, as well, the osteoblasts created bridges into the macropores, and filopodia was observed on all surfaces.

Alkaline phosphatase activity. Alkaline phosphate is the major marker characteristic of osteoblasts and is regarded as an early marker for osteoblast differentiation. It is known that an increase in the specific activity of ALP in a population of bone cells is associated with a corresponding shift toward to a more differentiated state. Although ALP is a premature marker, testing MC3T3 cultured on the bio-functionalized porous Ti surfaces may help understanding the process of bone tissue formation. ALP activity of the cells lysate measured for all bio-functionalized surfaces is presented in Figure 9. After differentiation, there was an increase on ALP activity for all samples except for Ti37-AT. The osteoblast differentiation occurred for Ti-AT and Ti22-AT groups. At 16 days of culture there was no significant different on ALP between Ti-AT and Ti22-AT samples. However, after 22 and 30 days of culture, ALP of Ti22-AT was 4 (0.46 and 1.97) and 5 (0.68 and 3.58) times higher than on Ti-AT, respectively.

\section{DISCUSSION}

As-etched and bio-functionalized Ti: Quantification and observation of fibroblasts growth

The basic biological studies to assess in vitro biocompatibility of a new material, and to determine the suitability of the 


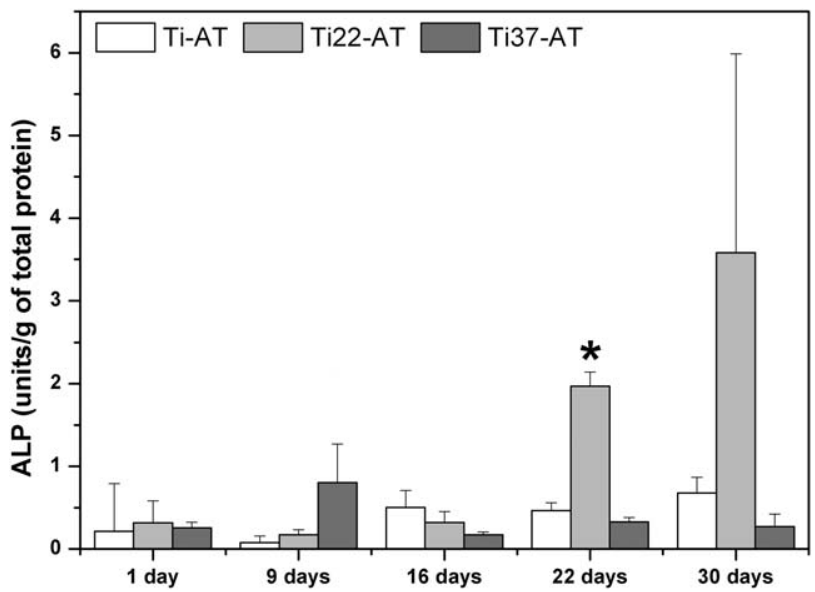

FIGURE 9. ALP activity of MC3T3-E1 cells cultured on different biofunctionalized porous Ti samples. * indicates significant difference compared all groups on relevant culture days $(p<0.05)$.

material for tissue engineering applications are considered as cell adhesion, morphology, and growth. Fibroblasts are commonly used to perform the in vitro biocompatibility studies since fibroblasts are cultivated without too much difficulty and present relatively high proliferation rate. ${ }^{53}$ Furthermore, it is known that osteoblast proliferation around the implant is the basis of in vivo osteointegration process. ${ }^{54}$ Moreover, it is known that microporosity leads to a larger surface area, contributes to higher bone-inducing protein adsorption, and improves the ion exchange and bonelike apatite formation. ${ }^{13,18}$ Also, it has been shown that the micro- or nanoscale topography can affect not only the apparent behavior of the cells, such as the direction or speed of migration, but also the functions of the cells, such as their signaling and differentiation. The knowledge of these cell-biomaterial interactions may suggest which modifications in the structure or composition of biomaterial can promote the recruitment of cells and bone tissue formation. ${ }^{51}$

According to Gittens et al., ${ }^{10}$ if the morphology and activity of fibroblast is enhanced by a tailored surface in terms of chemistry, it indicates that the surface is able to support soft tissue. The irregularities such as grain boundaries may act as cell anchorage, ${ }^{55}$ probably due to locally increased hardness and surface energy leading to improved cell migration. ${ }^{56}$

In order to overcome the lack of bioactivity of $\mathrm{Ti}$, the incorporation of bio-active elements as Ca and $\mathrm{P}$ are used. ${ }^{39,57-59}$ In the 1990 's, Ishizawa and Ogino ${ }^{45-49}$ used a Ca- and P-rich electrolyte for the MAO in order to incorporate these elements into the anodic layers and reported that by performing a hydrothermal treatment after MAO, several microcrystals of HAP were precipitated on the anodic oxide films containing $\mathrm{Ca}$ and $\mathrm{P}$, and this surface had osteoconductive property. Additionally, it is possible by MAO to obtain the formation of $\mathrm{TiO}_{2}$ in the form of anatase and rutile. ${ }^{30,39,60-63}$ Some authors ${ }^{61-64}$ had stated that $\mathrm{TiO}_{2}$ with structures of anatase and rutile induced the apatite formation in vitro. Kunzler et al. ${ }^{65}$ developed a surface modification process to develop roughness gradients ranging from 1.0 to $5.7 \mu \mathrm{m}$ on Ti surfaces. The authors carried out cells experiments using osteoblasts and fibroblasts. Fibroblasts showed a slightly higher initial attachment on the rough surface after 1 day of culture. After 2 days of culture, the number of fibroblasts did not show a significant increase on any position of the gradient. For values of $R_{\mathrm{a}}$ below $1.5 \mu \mathrm{m}$, the number of fibroblasts slightly increased after 4 days of culture. However, after 7 days of culture, the number of fibroblasts was significantly different for the different $R_{\mathrm{a}}$ values. The highest number of cells was found at surface zones with $R_{\mathrm{a}}$ values of 1.0 and 1.1 $\mu \mathrm{m}$. Some of the present authors had previously been reported that dense Ti samples bio-functionalized under identical conditions to the present study exhibited anodic layers having a mixture of anatase and rutile. ${ }^{43}$ Thus, the cell proliferation (Figure 4) may be attributed to the increased roughness of the surfaces after bio-functionalization together with the incorporation of the bio-active elements ( $\mathrm{Ca}$ and $\mathrm{P}$ ).

Xie et al. ${ }^{66}$ used anodic treatment to modify Ti surfaces in order to characterize fibroblasts adhesion. The authors showed that the number of cells on untreated Ti surfaces was significantly lower than the one on anodic treated surfaces. Moreover, fibroblasts were anchored onto the planes of the anodized surfaces. The fibroblasts appeared to be accommodated in the irregularly three-dimensional surface topography. Besides, the pseudopod of fibroblast cell was also interlocked in the submicron porous edge of the craters or grooves. From Figure 7 it was possible to observe that fibroblasts showed a good interaction with the biofunctionalized surfaces, as in accordance with the literature. ${ }^{17} \mathrm{Zhu}$ et al. ${ }^{17}$ produced graded $\mathrm{TiO}_{2}$ layer by MAO, having two layers of oxide films (rutile and anatase), and Ca- and P-rich porous surface layer. The fibroblasts attachment and the rate of proliferation were greater on the Caand P-rich surfaces when compared with untreated Ti surfaces. Moreover, Ribeiro et al. $^{39}$ reported that anodic layers developed with the same MAO parameters presented in the present study, were constituted by an oxide film with a graded structure where there was an increase of Ca-rich amorphous phase from the inner part to the outmost thicker part. The authors reported that cell adhesion was more effective on these outmost layers. This behavior was observed on the bio-functionalized surfaces (Figure 7) where the cell morphology lead to a better cell-cell interaction.

In vitro studies reported in the literature revealed that different ranges of porosity can promote different biofunctions. A recent study ${ }^{67}$ showed that Ti scaffolds with pore range between 45 and $106 \mu \mathrm{m}$ presented the best microarchitecture for early stages of attachment, presenting the higher number of cells, whereas pore range higher than $300 \mu \mathrm{m}$ exhibited the most favorable conditions for cell proliferation. On the other hand, Hollister ${ }^{14}$ stated that macropores up to $1000 \mu \mathrm{m}$ are crucial for tissue regeneration since they preserve tissue volume, provide temporary mechanical function, and allow the vascularization. The effect of pore size range was also reported in several studies in the literature. Gauthier et al. ${ }^{68}$ showed that after 8 weeks of in vivo implantation, better bone ingrowth was achieved for ceramic scaffolds with macropores of $565 \mu \mathrm{m}$ than $300 \mu \mathrm{m}$. On the other hand, Prananingrum et al. $^{1}$ 
showed that the pore size of $100 \mu \mathrm{m}$ presented the greatest amount of bone ingrowth, and the rate of bone ingrowth significantly decreased as the pore size increased on Ti scaffolds. Torres-Sanchez et al. ${ }^{67}$ concluded that small pores offer a larger surface area and at early days of culture this pore size is favorable for the attachment stage. However, when cell proliferation was dominant, larger pore size ranges also presented the largest growth rate, which confirms that large pore size supports cell growth.

Therefore, when the present results evaluated together with the reported studies in the literature, it can be stated that bio-functionalized macropores having $\mathrm{Ca}$ - and P-rich surfaces together with the typical roughness of anodic layers can help to promote the cell migration into the macropores. The present results displayed approximately 80 and $90 \%$ of the pores in the range of 50 and $350 \mu \mathrm{m}$ for Ti22 and Ti37, respectively. Therefore, it may be expected that the highly porous samples can be suitable both for early-stage attachment and cell proliferation. On the other hand, bio-functionalized surfaces showed an enhancement on the number of fibroblasts and fibroblast proliferation that may be mainly attributed to the altered topography, as well as altered chemical and structural composition, as also previously reported in the literature. ${ }^{17,39,40,42}$ Topographical measurements revealed that the present bio-functionalized samples exhibited surface roughness $\left(S_{\mathrm{a}}\right)$ values almost two times higher than as-etched samples (1.27 and $0.63 \mu \mathrm{m}$, respectively). Moreover, the results with fibroblasts revealed that both as-etched and bio-functionalized samples were biocompatible, but bio-functionalized samples combined the most favorable conditions for cell growth.

The results also showed a limited biological response on Ti37 and Ti37-AT samples in terms of cell proliferation and cell adhesion. However, it is worthy to state that the results obtained on these samples can be affected by the difficulties on measuring the number of cells on the interconnected inner pores. Therefore, further studies for estimating the number of cells through deoxyribose nucleic acid (DNA) assay are needed together with histological studies in order to understand the penetration of the cells to the most inner, interconnected pores.

\section{Osteoblastic differentiation on bio-functionalized $\mathrm{Ti}$}

The studies on quantification and observation of fibroblasts growth and cellularization revealed a better response on bio-functionalized surfaces, thus, this group of samples were selected to study the ability to promote the osteogenic response.

It has been reported that MAO treatment greatly promotes osteogenic differentiation at the initial stage of bone formation due to the morphology and crystalline phases of the MAO treated surfaces, leading to an excellent cytocompatibility in viability, adhesion, proliferation and differentiation of MC3T3-E1 preosteoblast. $^{61}$ As in accordance with the studies on the dense surfaces, bio-functionalized highly porous samples exhibited well attached and spread cells (Figure 8). However, although ALP was enhanced in Ti22-AT group as compared to Ti-AT, a decrease was observed on
Ti37-AT samples. This behavior may be due to the difficulty to lyse the cells in the most inner and interconnected pores, together with the fact that the cell signal may be diluted by the remaining medium. Therefore, this particular result should be interpreted with cautious as it can reflect a technical hindrance inherent of the Ti37-AT samples.

Conventionally, osteoblast recruitment to bone defects and subsequent bone repair has been achieved using growth factors. It was reported in the literature that intracellular dissolution of calcium containing surfaces greatly influences osteoblasts behavior. ${ }^{55}$ The interaction of osteoblasts with the bio-functionalized dense Ti6Al4V surfaces had recently been reported by Hall et al. ${ }^{69}$ as to be improved after in vivo studies on hip arthroplasty femoral stems. The authors performed a study on a 6-month canine model and reported that the anodic treatment had a significant effect on bone ingrowth and soft tissue response on the total hip replacement femoral stem.

The enhanced biological results on the biofunctionalized surfaces may be related with surface energy, roughness, and chemistry that influence protein adsorption which promotes cell adhesion. ${ }^{70}$ Moreover, Ti anodic films are known as having high surface energy which is essential for maintaining surface hydrophilicity that enhance adsorption of fibronectin. ${ }^{71}$ Jimbo et al. $^{70}$ reported that higher amount of collagen type I adsorbed onto Ti anodic treated surfaces was found when compared with untreated Ti surfaces. Therefore, in addition to these advantages of the biofunctionalized surfaces presented in the literature, the biofunctionalized highly porous $\mathrm{Ti}$ developed in the present work has a potential of offering further advantages such as reduced Young's modulus and bone ingrowth in a macroscale. Based on these facts, the present authors suggest that bio-functionalized highly porous $\mathrm{Ti}$ can be considered for orthopedic implant applications. Nevertheless, further studies need to be performed in order to define the optimum macroporosity percentage in terms of biological and mechanical response. The present results also showed that the process of bone formation can be started on this type of bio-functionalized biomaterial surface, but this should be confirmed by quantifying proteins that are late markers of osteoblast differentiation such as BSP, osteocalcin, osteopontin, collagen type 1 and/or by studying the expression of messenger ribonucleic acid for Runx2, BSP, OCN, ALP, and COL I gene.

\section{CONCLUSIONS}

The combined influence of the 3D macroporous architecture and bio-functionalization on the biological response of $\mathrm{Ti}$ was accessed by cell adhesion, proliferation, and osteogenic differentiation. Within the as-etched samples, enhanced results both in terms of cell adhesion and proliferation of NIH/3T3 was obtained on Ti22 samples.

The bio-functionalization was performed by MAO using a Ca- and P-rich electrolyte. The bio-functionalized samples exhibited better adhesion and proliferation of NIH/3T3 cells when compared to as-etched control samples, that was 
attributed to the chemical composition, crystalline structure (mixture of anatase and rutile), and topography of the anodic layers. Moreover, the way that fibroblasts and osteoblasts spread on the surface during cell culture was comparable, both showing very similar morphologies/behavior. However, the bio-functionalization did not affect the cell viability.

Within the tested bio-functionalized samples, the ALP activity was enhanced on Ti22-AT samples, indicating that the osteogenic differentiation at the initial stage of bone formation was improved. These results showed that biofunctionalized highly porous $\mathrm{Ti}$ can be considered as an implant material for orthopaedic applications. Results also showed that bio-functionalization by MAO was efficient on the incorporation of $\mathrm{Ca}$ and $\mathrm{P}$ not only to the outmost surfaces, but also to the inner pore surfaces, which may allow the supply of bioactive elements when necessary. Moreover, biological results showed improved biocompatibility in terms of cell adhesion, proliferation, and differentiation. Nevertheless, in order to validate the proposed novel system, in vivo experiments associated with shear fatigue and microdisplacement (fretting fatigue) tests in the field of biomechanics are needed.

\section{ACKNOWLEDGMENTS}

The authors would also like to thank for their kind help to Cryril Breton from LGPM and Eric Perrin from MSSMat for characterization studies.

\section{REFERENCES}

1. Prananingrum W, Naito $Y$, Galli S, Bae J, Sekine K, Hamada K, Tomotake $\mathrm{Y}$, Wennerberg A, Jimbo R, Ichikawa T. Bone ingrowth of various porous titanium scaffolds produced by a moldless and space holder technique: An in vivo study in rabbits. Biomed Mater 2016;11:15012.

2. Sun J, Yao QT, Zhang YH, Du XD, Wu YC, Tong WP. Simultaneously improving surface mechanical properties and in vitro biocompatibility of pure titanium via surface mechanical attrition treatment combined with low-temperature plasma nitriding. Surf Coat Technol 2017;309:382-389.

3. Ryan G, Pandit A, Apatsidis DP. Fabrication methods of porous metals for use in orthopaedic applications. Biomaterials 2006;27: 2651-2670.

4. Wu Y, Zitelli JP, Ten Huisen KS, Yu X, Libera MR. Differential response of Staphylococci and osteoblasts to varying titanium surface roughness. Biomaterials 2011;32:951-960.

5. Barui S, Chatterjee S, Mandal S, Kumar A, Basu B. Microstructure and compression properties of 3D powder printed Ti-6Al-4V scaffolds with designed porosity: Experimental and computational analysis. Mater Sci Eng C 2017;70:812-823.

6. Kirmanidou $Y$, Sidira M, Drosou ME, Bennani V, Bakopoulou A, Tsouknidas A, Michailidis N, Michalakis K. New Ti-Alloys and Surface Modifications to Improve the Mechanical Properties and the Biological Response to Orthopedic and Dental Implants: A Review. Biomed Res Int. 2016;2016:1-21.

7. Chen J, Chen L, Chang CC, Zhang Z, Li W, Swain M V., Li Q. Micro-CT based modelling for characterising injection-moulded porous titanium implants. Int J Numer Method Biomed Eng 2017; 33:1-14.

8. Daudt N de F, Bram M, Barbosa APC, Laptev AM, Alves C. Manufacturing of highly porous titanium by metal injection molding in combination with plasma treatment. J Mater Process Technol 2017;239:202-209.

9. Simoneau C, Terriault $P$, Jetté B, Dumas $M$, Brailovski V. Development of a porous metallic femoral stem: Design, manufacturing, simulation and mechanical testing. Mater Des 2017;114:546-556.

10. Gittens RA, Scheideler L, Rupp F, Hyzy SL, Geis-Gerstorfer J, Schwartz Z, Boyan BD. A review on the wettability of dental implant surfaces II: Biological and clinical aspects. Acta Biomater 2014;10:2907-2918.

11. Murphy CM, Haugh MG, O'Brien FJ, The effect of mean pore size on cell attachment, proliferation and migration in collagenglycosaminoglycan scaffolds for bone tissue engineering. Biomaterials 2010;31:461-466.

12. Khoda AKM, Ozbolat IT, Koc B. Designing heterogeneous porous tissue scaffolds for additive manufacturing processes. CAD Comput Aided Des 2013;45:1507-1523.

13. Karageorgiou V, Kaplan D. Porosity of 3D biomaterial scaffolds and osteogenesis. Biomaterials 2005;26:5474-5491.

14. Hollister SJ. Porous scaffold design for tissue engineering. Nat Mater 2005;4:518-524.

15. Albrektsson T, Johansson C. Osteoinduction, osteoconduction and osseointegration. Eur Spine J 2001;10:S96-S101.

16. Geng $Z$, Wang $R$, Zhuo $X$, Li Z, Huang $Y$, Ma L, Cui Z, Zhu S, Liang Y, Liu Y, Bao H, Li X, Huo Q, Liu Z, Yang X. Incorporation of silver and strontium in hydroxyapatite coating on titanium surface for enhanced antibacterial and biological properties. Mater Sci Eng C 2017;71:852-861.

17. Zhu L, Ye X, Tang G, Zhao N, Gong Y, Zhao Y, Zhao J, Zhang $X$ Corrosion test, cell behavior test, and in vivo study of gradient TiO2 layers produced by compound electrochemical oxidation. J Biomed Mater Res 2006;78A:515-522.

18. Yuan H, Kurashina K, De Bruijn JD, Li Y, De Groot K, Zhang X. A preliminary study on osteoinduction of two kinds of calcium phosphate ceramics. Biomaterials 1999;20:1799-1806.

19. Coelho PG, Granjeiro JM, Romanos GE, Suzuki M, Silva NRF, Cardaropoli G, Van Thompson $P$, Lemons JE. Basic research methods and current trends of dental implant surfaces. J Biomed Mater Res B 2009;88:579-596.

20. Salerno M, Itri A, Frezzato M, Rebaudi A. Surface microstructure of dental implants before and after insertion: An in vitro study by means of scanning probe microscopy. Implant Dent 2015;24: 248.

21. Park JW, Kim YJ, Jang JH, Kwon TG, Bae YC, Suh JY. Effects of phosphoric acid treatment of titanium surfaces on surface properties, osteoblast response and removal of torque forces. Acta Biomater 2010;6:1661-1670.

22. Deporter DA, Watson PA, Pilliar RM, Chipman ML, Valiquette N. A histological comparison in the dog of porous-coated vs. threaded dental implants. J Dent Res 1990;69:1138-1145.

23. Baril E, Lefebvre LP, Hacking SA. Direct visualization and quantification of bone growth into porous titanium implants using micro computed tomography. J Mater Sci Mater Med 2011;22: 1321-1332.

24. Vasconcellos LMR, Oliveira M V., Graça MLA, Vasconcellos LGO, Cairo CAA, Carvalho YR. Design of dental implants, influence on the osteogenesis and fixation. J Mater Sci Mater Med 2008;19: 2851-2857.

25. Wazen RM, Lefebvre L-P, Baril E, Nanci A. Initial evaluation of bone ingrowth into a novel porous titanium coating. J Biomed Mater Res B 2010;94:64-71

26. Kuboki $Y$, Takita $H$, Kobayashi D, Tsuruga $E$, Inoue $M$, Murata $M$, Nagai N, Dohi $Y$, Ohgushi H. BMP-induced osteogenesis on the surface of hydroxyapatite with geometrically feasible and nonfeasible structures: Topology of osteogenesis. J Biomed Mater Res 1998;39:190-199.

27. Murphy CM, O'Brien FJ. Understanding the effect of mean pore size on cell activity in collagen-glycosaminoglycan scaffolds. Cell Adhes Migr 2010;4:377-381.

28. Peng $W, X u L$, You J, Fang L, Zhang $Q$. Selective laser melting of titanium alloy enables osseointegration of porous multi-rooted implants in a rabbit model. Biomed Eng Online. BioMed Central; 2016;15:1-13.

29. Bae IH, Yun KD, Kim HS, Jeong BC, Lim HP, Park SW, Lee KM, Lim YC, Lee KK, Yang Y, Koh JT. Anodic oxidized nanotubular titanium implants enhance bone morphogenetic protein-2 delivery. J Biomed Mater Res B 2010;93:484-491. 
30. Oliveira FG, Ribeiro AR, Perez G, Archanjo BS, Gouvea CP, Araújo JR, Campos APC, Kuznetsov A, Almeida CM, Maru MM, Achete CA, Ponthiaux $P$, Celis J-P, Rocha LA. Understanding growth mechanisms and tribocorrosion behaviour of porous $\mathrm{TiO}_{2}$ anodic films containing calcium, phosphorous and magnesium. Appl Surf Sci 2015;341:1-12.

31. Echeverry-Rendón M, Galvis O, Quintero Giraldo D, Pavón J, López-Lacomba JL, Jiménez-Piqué $E$, Anglada M, Robledo SM, Castaño JG, Echeverría F. Osseointegration improvement by plasma electrolytic oxidation of modified titanium alloys surfaces. J Mater Sci Mater Med 2015;26:1-18.

32. Gorgin Karaji Z, Hedayati R, Pouran B, Apachitei I, Zadpoor AA. Effects of plasma electrolytic oxidation process on the mechanical properties of additively manufactured porous biomaterials. Mater Sci Eng C 2017;76:406-416.

33. Amin Yavari S, Ahmadi SM, Van der Stok J, Wauthle R, Riemslag AC, Janssen M, Schrooten J, Weinans H, Zadpoor AA. Effects of bio-functionalizing surface treatments on the mechanical behavior of open porous titanium biomaterials. J Mech Behav Biomed Mater 2014;36:109-119.

34. Khodaei M, Meratian M, Savabi O, Fathi M, Ghomi H. The side effects of surface modification of porous titanium implant using hydrogen peroxide: Mechanical properties aspects. Mater Lett 2016;178:201-204.

35. Khodaei M, Valanezhad A, Watanabe I, Yousefi R. Surface and mechanical properties of modified porous titanium scaffold. Surf Coat Technol 2017:315:61-66.

36. Sul YT, Kang BS, Johansson C, Um HS, Park CJ, Albrektsson T. The roles of surface chemistry and topography in the strength and rate of osseointegration of titanium implants in bone. J Biomed Mater Res A 2009;89:942-950.

37. Ou K-L, Weng C-C, Lin Y-H, Huang M-S. A promising of alloying modified beta-type titanium-niobium implant for biomedical applications: Microstructural characteristics, in vitro biocompatibility and antibacterial performance. J Alloys Compd 2017;697: 231-238.

38. Alves SA, Bayón R, de Viteri VS, Garcia MP, Igartua A, Fernandes $\mathrm{MH}$, Rocha LA. Tribocorrosion behavior of calcium- and phosphorous-enriched titanium oxide films and study of osteoblast interactions for dental implants. J Bio Tribo Corros 2015;1:23.

39. Ribeiro AR, Oliveira $F$, Boldrini LC, Leite PE, Falagan-Lotsch $P$, Linhares ABR, Zambuzzi WF, Fragneaud B, Campos APC, Gouvêa CP, Archanjo BS, Achete CA, Marcantonio E, Rocha LA, Granjeiro JM. Micro-arc oxidation as a tool to develop multifunctional calcium-rich surfaces for dental implant applications. Mater Sci Eng C 2015;54:196-206.

40. Liu J, Wang P, Chu C-C, Xi T. A novel biodegradable and biologically functional arginine-based poly(ester urea urethane) coating for $\mathrm{Mg}-\mathrm{Zn}-\mathrm{Y}-\mathrm{Nd}$ alloy: Enhancement in corrosion resistance and biocompatibility. J Mater Chem B 2017;5:1787-802.

41. Wu G, Li $P$, Feng $H$, Zhang $X$, Chu PK. Engineering and functionalization of biomaterials via surface modification. J Mater Chem B 2015;3:2024-2042.

42. Wang $C$, Fan Z, Han Y. Formation and osteoblast behavior of HA nano-rod/fiber patterned coatings on tantalum in porous and compact forms. J Mater Chem B 2015;3:5442-5454.

43. Toptan F, Alves AC, Pinto AMP, Ponthiaux P. Tribocorrosion behavior of bio-functionalized highly porous titanium. J Mech Behav Biomed Mater 2017;69:144-1452.

44. Teker D, Muhaffel F, Menekse M, Karaguler NG, Baydogan M, Cimenoglu $\mathrm{H}$. Characteristics of multi-layer coating formed on commercially pure titanium for biomedical applications. Mater Sci Eng C 2015;48:579-585.

45. Ishizawa $\mathrm{H}$, Ogino $\mathrm{M}$. Characterization of thin hydroxyapatite layers formed on anodic titanium oxide films containing $\mathrm{Ca}$ and $\mathrm{P}$ by hydrothermal treatment. J Biomed Mater Res 1995;29:10711079.

46. Ishizawa $\mathrm{H}$, Ogino $\mathrm{M}$. Formation and characterization of anodic titanium oxide films containing $\mathrm{Ca}$ and $\mathrm{P}$. J Biomed Mater Res 1995;29:65-72.

47. Ishizawa H, Ogino M. Hydrothermal precipitation of hydroxyapatite on anodic titanium oxide films containing $\mathrm{Ca}$ and $\mathrm{P}$. J Mater Sci 1999;34:5893-5898.
48. Ishizawa $H$, Fujino $M$, Ogino $M$. Histomorphometric evaluation of the thin hydroxyapatite layer formed through anodization followed by hydrothermal treatment. J Biomed Mater Res 1997;35: 199-206.

49. Ishizawa $H$, Fujino $M$, Ogino $M$. Mechanical and histological investigation of hydrothermally treated and untreated anodic titanium oxide films containing $\mathrm{Ca}$ and P. J Biomed Mater Res 1995; 29:1459-1468.

50. Carré $A$, Lacarrière $V$. How substrate properties control cell adhesion. A physical-chemical approach. J Adhes Sci Technol. 2010; 24:815-830.

51. Takamori ER, Cruz R, Gonçalvez F, Zanetti RV, Zanetti A, Granjeiro JM. Effect of roughness of zirconia and titanium on fibroblast adhesion. Artif Org 2008;32:305-309.

52. Alves AC, Sendão I, Ariza E, Toptan F, Ponthiaux P, Pinto AMP. Corrosion behaviour of porous $\mathrm{Ti}$ intended for biomedical applications. J Porous Mater 2016;23:1261-1268.

53. Wirth C, Comte V, Lagneau C, Exbrayat P, Lissac M, JaffrezicRenault N, Ponsonnet L. Nitinol surface roughness modulates in vitro cell response: A comparison between fibroblasts and osteoblasts. Mater Sci Eng C 2005;25:51-60.

54. Naddeo P, Laino L, La Noce M, Piattelli A, De Rosa A, lezzi G, Laino G, Paino F, Papaccio G, Tirino V. Surface biocompatibility of differently textured titanium implants with mesenchymal stem cells. Dent Mater 2015;31:235-243.

55. Begam H, Kundu B, Chanda A, Nandi SK. MG63 osteoblast cell response on $\mathrm{Zn}$ doped hydroxyapatite (HAp) with various surface features. Ceram Int 2016;43:3752-3760.

56. Dohan Ehrenfest DM, Coelho PG, Kang BS, Sul YT, Albrektsson T. Classification of osseointegrated implant surfaces: Materials, chemistry and topography. Trends Biotechnol 2010;28:198-206.

57. Alves SA, Bayón R, Igartua A, Saénz de Viteri V, Rocha LA. Tribocorrosion behaviour of anodic titanium oxide films produced by plasma electrolytic oxidation for dental implants. Lubr Sci 2014; 26:500-513.

58. Felgueiras HP, Castanheira L, Changotade S, Poirier F, Oughlis S, Henriques M, Chakar C, Naaman N, Younes R, Migonney V, Celis JP, Ponthiaux P, Rocha LA, Lutomski D. Biotribocorrosion (triboelectrochemical) characterization of anodized titanium biomaterial containing calcium and phosphorus before and after osteoblastic cell culture. J Biomed Mater Res B 2014;103:661-669.

59. Li L-H, Kong Y-M, Kim H-W, Kim Y-W, Kim H-E, Heo S-J, Koak J-Y. Improved biological performance of $\mathrm{Ti}$ implants due to surface modification by microarc oxidation. Biomaterials 2004;25:2867-2875.

60. Alves AC, Oliveira F, Wenger F, Ponthiaux P, Celis J-P, Rocha LA Tribocorrosion behaviour of anodic treated titanium surfaces intended for dental implants. J Phys D Appl Phys 2013;46:404001.

61. Wang Y, Lou J, Zeng L, Xiang J, Zhang S, Wang J, Xiong F, Li C, Zhao $Y$, Zhang R. Osteogenic potential of a novel microarc oxidized coating formed on Ti6Al4V alloys. Appl Surf Sci 2017;412: 29-36.

62. Yang B, Uchida M, Kim HM, Zhang X, Kokubo T. Preparation of bioactive titanium metal via anodic oxidation treatment. Biomaterials 2004;25:1003-1010.

63. Park YJ, Shin KH, Song HJ. Effects of anodizing conditions on bond strength of anodically oxidized film to titanium substrate. Appl Surf Sci 2007;253:6013-6018.

64. He G, Guo B, Wang H, Liang C, Ye L, Lin Y, Cai X. Surface characterization and osteoblast response to a functionally graded hydroxyapatite/fluoro-hydroxyapatite/titanium oxide coating on titanium surface by sol-gel method. Cell Prolif 2014;47:258-266.

65. Kunzler TP, Drobek T, Schuler M, Spencer ND. Systematic study of osteoblast and fibroblast response to roughness by means of surface-morphology gradients. Biomaterials 2007:28:2175-2182.

66. Xie L, Yin G, Yan D, Liao X, Huang Z, Yao Y, Kang Y, Liu Y. Structure, morphology and fibroblasts adhesion of surface-porous titanium via anodic oxidation. J Mater Sci Mater Med 2010;21:259-266.

67. Torres-sanchez C, Mushref FRA Al, Norrito M, Yendall K, Liu Y, Conway PP. The effect of pore size and porosity on mechanical properties and biological response of porous titanium scaffolds. Mater Sci Eng C 2017;77:219-228.

68. Gauthier O, Bouler JM, Aguado E, Pilet P, Daculsi G. Macroporous biphasic calcium phosphate ceramics: Influence of 
macropore diameter and macroporosity percentage on bone ingrowth. Biomaterials 1998;19:133-139.

69. Hall DJ, Urban RM, Pourzal R, Turner TM, Skipor AK, Jacobs JJ. Nanoscale surface modification by anodic oxidation increased bone ingrowth and reduced fibrous tissue in the porous coating of titanium? Alloy femoral hip arthroplasty implants. J Biomed Mater Res B 2017;105:283-290.
70. Jimbo R, Ivarsson M, Koskela A, Sul Y-T, Johansson CB. Protein adsorption to surface chemistry and crystal structure modification of titanium surfaces. J Oral Maxillofac Res 2010;1:1-9.

71. Keselowsky BG, Collard DM, García AJ. Surface chemistry modulates fibronectin conformation and directs integrin binding and specificity to control cell adhesion. J Biomed Mater Res A 2003; 66:247-259. 